\title{
Macadamia responses to mild water stress at different phenological stages
}

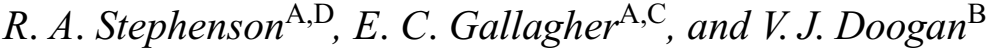 \\ ${ }^{\mathrm{A}}$ Maroochy Research Station, Centre for Subtropical Fruit, Queensland Horticulture Institute, \\ Department of Primary Industries, PO Box 5083, SCMC, Nambour, Qld 4560, Australia. \\ ${ }^{\mathrm{B}}$ Queensland Department of Primary Industries, Biometry, Locked Bag No. 4, Moorooka, \\ Qld 4105, Australia. \\ ${ }^{\mathrm{C}}$ Retired. \\ ${ }^{\mathrm{D}}$ Corresponding author; email: russ.stephenson@dpi.qld.gov.au
}

\begin{abstract}
Mild water stress was imposed on bearing macadamia trees in through-draining lysimeters at various phenological stages. Water was withheld until a xylem water potential $\left(\Psi_{\mathrm{x}}\right)$ of -1.5 to $2.0 \mathrm{MPa}$ was reached, this being maintained by partial water replenishment at 2-day intervals. Flowering, nut set, nut development, yield, and quality responses were assessed to identify critical, stress-sensitive stages. Stress during nut maturation was particularly detrimental to both yield and quality, although stress during floral development and the premature nut drop also had adverse effects. Low yields were due to reduced nut number and smaller nuts. Lower photosynthesis (c. $2 \mu \mathrm{mol} \mathrm{CO} \mathrm{CO}_{2} / \mathrm{m}^{2}$.s) at $-1.5 \mathrm{MPa}$ would account for reduced yield and poorer quality during nut maturation when energy demands of active oil accumulation are high. Stress at floral initiation was generally not detrimental.

Overall, stress restricted growth. The rate of girth growth was significantly lower when stress was applied during the dormant floral initiation stage. When stress coincided with normal periods of vegetative growth, flushing was delayed until after re-watering when greater foliage production was stimulated. Judiciously imposing mild stress may be used to manipulate macadamia phenology, although it may not necessarily conserve water. Further refinement would be needed to develop stress manipulation as a practical and reliable management tool to achieve higher yields.

Water should be applied to alleviate stress during critical stages of nut development and maturation. Mild stress after the current crop is mature, however, is unlikely to be detrimental to macadamia yield or quality. It may, in fact, be beneficial through manipulation of flushing patterns that influence yield.
\end{abstract}

Additional keywords: yield, quality, kernel recovery, first grade kernel, photosynthesis, water potential, stomatal conductance, water use.

\section{Introduction}

In many macadamia (Macadamia integrifolia) growing areas of Australia, South Africa, and Hawaii, quantity and/or distribution of rainfall is often inadequate to sustain high yields, and water available for irrigation is often limited. An understanding of tree water requirements is desirable to improve irrigation efficiency. Since macadamia trees have several characteristics that enable them to endure relatively dry conditions, stress at non-critical stages may not be reflected in depressed yields or inferior quality. In fact, Grierson et al. (1982) document the beneficial manipulation of physiological stresses of various kinds, particularly those influencing ontogeny. By imposing mild water stress at appropriate, non-critical times, limited water resources could be reserved for critical phenological stages at which yield and/or quality would otherwise be adversely affected.

A preliminary study (Stephenson et al. 1989b) described responses of young, potted, vegetative macadamia trees to gradually developing water stress. After 2 weeks of withholding water, relative water content declined to $c .50 \%$ (from an initial $90 \%$ when trees were well watered) and xylem water potential $\left(\Psi_{\mathrm{x}}\right)$ to $-4.0 \mathrm{MPa}$ or less. Stomatal conductance declined sharply by $80 \%$ at $\Psi_{\mathrm{x}}$ of less than -2.4 $\mathrm{MPa}$. Mature, hardened leaves, however, did not develop visible stress symptoms until $\Psi$ of $-4.1 \mathrm{MPa}$ was reached. Irreversible damage to leaves occurred when $\Psi$ declined beyond $-5.0 \mathrm{MPa}$. 
Table 1. Water required by macadamia trees during the stressing cycle to maintain mild stress ( $-1.5 \mathrm{MPa})$, and duration of stress at different phenological stages over a 6-year period

\begin{tabular}{|c|c|c|c|c|c|c|}
\hline Treatments & $1989-90$ & $1990-91$ & $1991-92$ & $1992-93$ & $1993-94$ & $1994-95$ \\
\hline \multicolumn{7}{|c|}{ Mean daily water consumption (L/tree.day) } \\
\hline Floral initiation (Apr.) & - & 4.6 & 14 & 13.7 & 31.8 & 23.2 \\
\hline Floral development (July-Aug.) & 4.76 & 10.6 & 30.6 & 28.8 & 23.5 & 24.3 \\
\hline Premature nut drop (Nov.) & 4.4 & 15.2 & 22 & 32.8 & 27.0 & 43.8 \\
\hline Nut maturation (Dec.) & 16.3 & 21.8 & 23.4 & 41.3 & 45.6 & 53.6 \\
\hline \multicolumn{7}{|c|}{ Duration of stress (days) } \\
\hline Floral initiation (Apr.) & - & 72.3 & 57.3 & 68 & 34.7 & 35 \\
\hline Floral development (July-Aug.) & 42 & 76.5 & 35.3 & 29 & 33.5 & 23.8 \\
\hline Premature nut drop (Nov.) & 67.7 & 66.0 & 55.3 & 32.5 & 33.3 & 21.3 \\
\hline Nut maturation (Dec.) & 53.7 & 96.5 & 58.8 & 32.3 & 31.8 & 22.3 \\
\hline
\end{tabular}

The present study identifies critical phenological stages during which water stress adversely affects yield and quality, and the extent to which trees can withstand stress during non-critical stages. Implications for efficient irrigation strategies that maximise the benefits of scarce water resources are discussed.

\section{Materials and methods}

In 1983, clonal macadamia trees, 'Keauhou' (HAES 246), were transplanted into a sandy soil in a through-draining lysimeter facility previously described by Stephenson et al. (1988). The trees were grown from cuttings to reduce genetic variability. All trees were provided with non-limiting water until 1989, 2 years after bearing had commenced. Tank dimensions ( $3 \mathrm{~m}$ diameter by $1.6 \mathrm{~m}$ deep) were designed to allow extensive root development similar to that in commercial orchards. Nevertheless, as trees approached maturity, root development may have been restricted. Observations during the experiment and the results of the destructive harvest at completion, however, suggest that tree and root growth was normal. Flowmeters were used to measure the water applied to each lysimeter tank and through-drainage water was collected and measured, the difference being transpiration losses from the tree since the previous replenishment to field capacity. Raincovers were used to divert rainwater from lysimeter tanks and 2 sets of control treatments (one with and one without raincovers) were used to assess their effect on trees. Except for trees being subjected to stress treatments, trees were maintained stress-free by maintaining the soil at field capacity. Soil moisture was monitored regularly with tensiometers and a neutron moisture meter.

Annual soil and leaf analysis, as described by Stephenson et al. (1986b) and Stephenson and Gallagher (1989), was carried out and nutrition adjusted, as necessary, to ensure that nutrients were non-limiting. Similarly, insect population and disease levels were monitored regularly to ensure that non-treatment effects were minimal.

Based on the results of the preliminary study, mild levels of stress (initially $\Psi_{\mathrm{x}}$ of $-2.0 \mathrm{MPa}$ and subsequently reduced to $-1.5 \mathrm{MPa}$ ) were imposed on trees at floral initiation (April), floral development (July-August), premature nut drop (November), and nut maturation (the beginning of nut maturation and oil accumulation, December). The same treatments were applied to the same trees throughout the experiment. Responses were compared with unstressed trees both with and without raincovers.

Stress levels were monitored daily (early morning) using a pressure chamber (Scholander et al. 1964) with modifications suggested by Ritchie and Hinkley (1975), and partial water replenishment was provided when pre-determined stress levels of $-1.5 \mathrm{MPa}$ were reached pre-dawn during the stressing cycle. The corresponding water potential of unstressed trees was $c$. $-0.5 \mathrm{MPa}$ or less. The quantities of water applied to trees to maintain these stress levels are shown in Table 1. Depending on water use, replenishment was usually provided every second day. The number of days during which stress was imposed was adjusted annually to narrow down the critical time of exposure to mild stress. In the 1990-91 season, for example, stress was maintained for 70 days for floral initiation, flowering, nut set, and nut drop stages and 96 days for the oil accumulation stage. Periods of stress were progressively reduces each year to $35,24,21$, and 22 days in the 1994-95 season (Table 1).

Soil moisture was measured with tensiometers and a neutron probe (Campbell Scientific). A nearby weather station recorded atmospheric conditions. Vapour pressure deficit was measured using a wet-bulb sling psychrometer. Photosynthesis and stomatal conductance were measured on a LI6200 portable photosynthesis system during different seasons over a 3-year period.

Responses to mild stress were assessed on the basis of tree growth, flowering intensity, nut set, nut drop and nut growth, yield, and quality. Infloresence numbers were counted on 5 representative subsample branches. Nuts were harvested at regular intervals (c. 5-7 harvests), divided into husk, shell, and kernel, and oven-dried at $60^{\circ} \mathrm{C}$, and subsamples from harvests 5-7 only were taken for quality assessment because of the usual early season variability. Kernel recovery was determined by weight (kernel/nut-in-shell $\times 100)$ and first grade kernel by flotation in water ( specific gravity of $1=72 \%$ oil or more $=$ first grade kernel).

The trial design was a randomised complete block with 6 treatments and 4 replicate blocks with single tree plots, a total of 24 trees, each in a separate lysimeter tank. Statistical analysis was carried out on data from years 1991 to 1995 . Some data were excluded from the analysis. From 1991 to 1995, data from 2 smaller replants that replaced wind-damaged trees were excluded; from 1992 to 1995 , data from a sick tree were excluded; and from 1993 to 1995 , data from another sick tree were also excluded from the analysis. All analyses were conducted using the statistical package GENSTAT (2000). Analysis of variance was used to assess the effect of treatments on yield and quality parameters in each year of harvest. Treatment means were compared using the protected least significant difference procedure with a significance level of $P=0.05$. Due to the missing values in the data, the standard deviation is presented as the measure of variability and the postscript lettering system is used to indicate differences between treatment means. Comparison of linear regressions was used to compare the tree girth data over time for the 6 treatments.

\section{Results}

\section{Water use}

Unstressed trees extracted water from the top $70 \mathrm{~cm}$ of soil, whereas it was rapidly depleted to $40 \mathrm{~cm}$ by the surface mat 


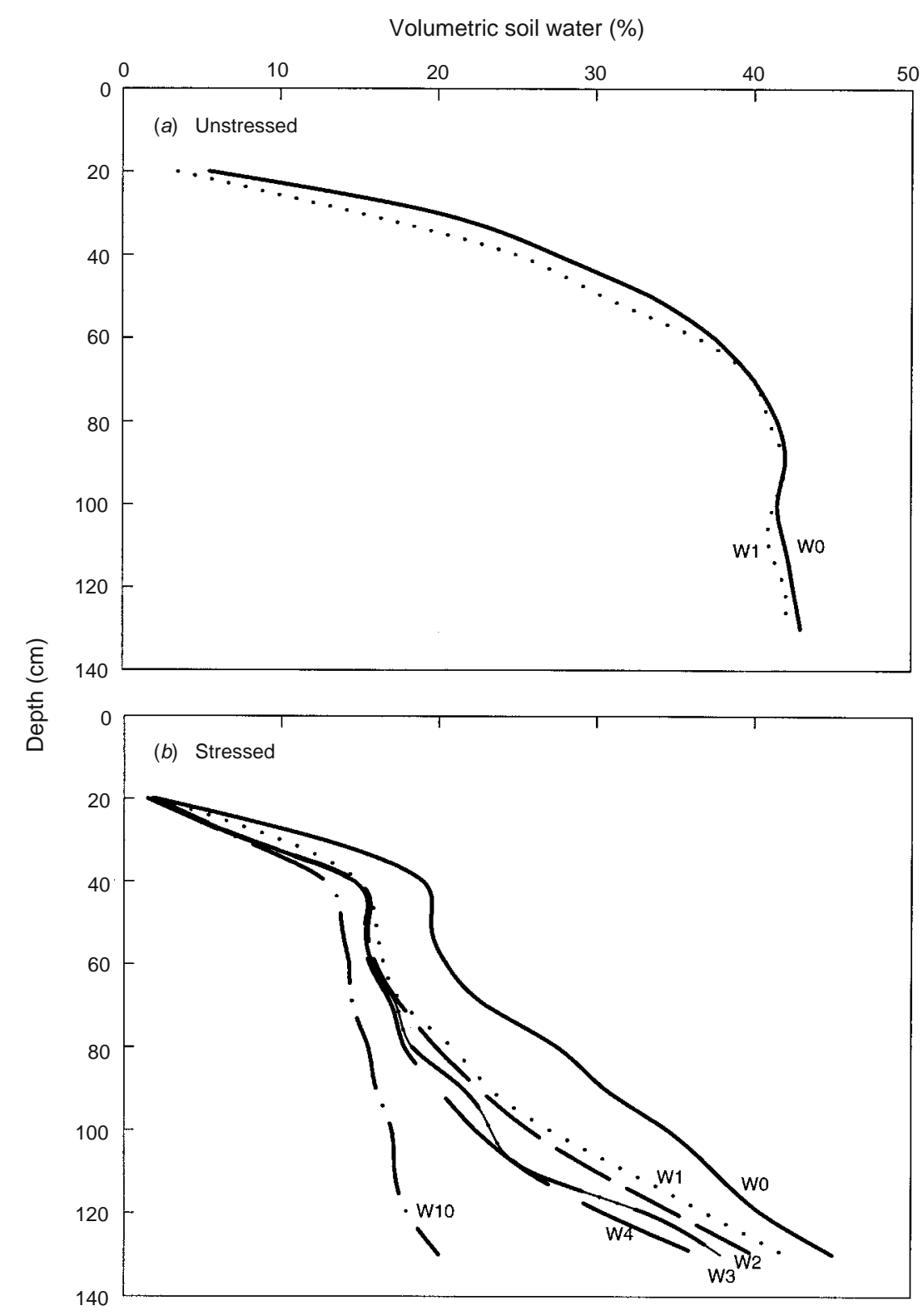

Fig. 1. Weekly soil moisture profiles under (a) unstressed and (b) stressed ( $-1.5 \mathrm{MPa})$ macadamia cv. Keauhou trees growing in lysimeter tanks during a typical stressing cycle (in July-August 1990). Weeks after stressing are indicated by W.

of roots of stressed trees (Fig. 1). The prolonged stressing cycle reflects the limited root system of this young tree. As trees developed, similar water extraction patterns were observed but the stressing cycle was reduced due to more extensive root systems. Further water extraction by stressed trees occurred at greater depth $(>130 \mathrm{~cm})$ thereafter, leaving only $10 \%$ of soil moisture through the profile towards the end of the stressing cycle. Subsequently, partial water replenishment provided to maintain mild stress only wetted close to the soil surface. There was relatively little change in soil water status under unstressed trees compared with that under stressed tress. Mean daily water use across the season was similar ( $75 \mathrm{~L} /$ tree.day), overall, in both stressed and unstressed trees. Water consumption peaked in summer with an average of $80.2 \mathrm{~L} /$ tree.day and declined to $51.7 \mathrm{~L} /$ tree.day in winter.

\section{Physiological responses}

Figure 2 shows that the water status of racemes was much lower $(c .-2.3 \mathrm{MPa})$ than that of leaves $(c .-1.5 \mathrm{MPa})$ on mildly stressed trees at the stage of floral development (August 1992) compared with those on unstressed trees (c. -1.2 and $-1.0 \mathrm{Mpa}$, respectively). Stomatal conductance of leaves from stressed trees was only marginally lower than 


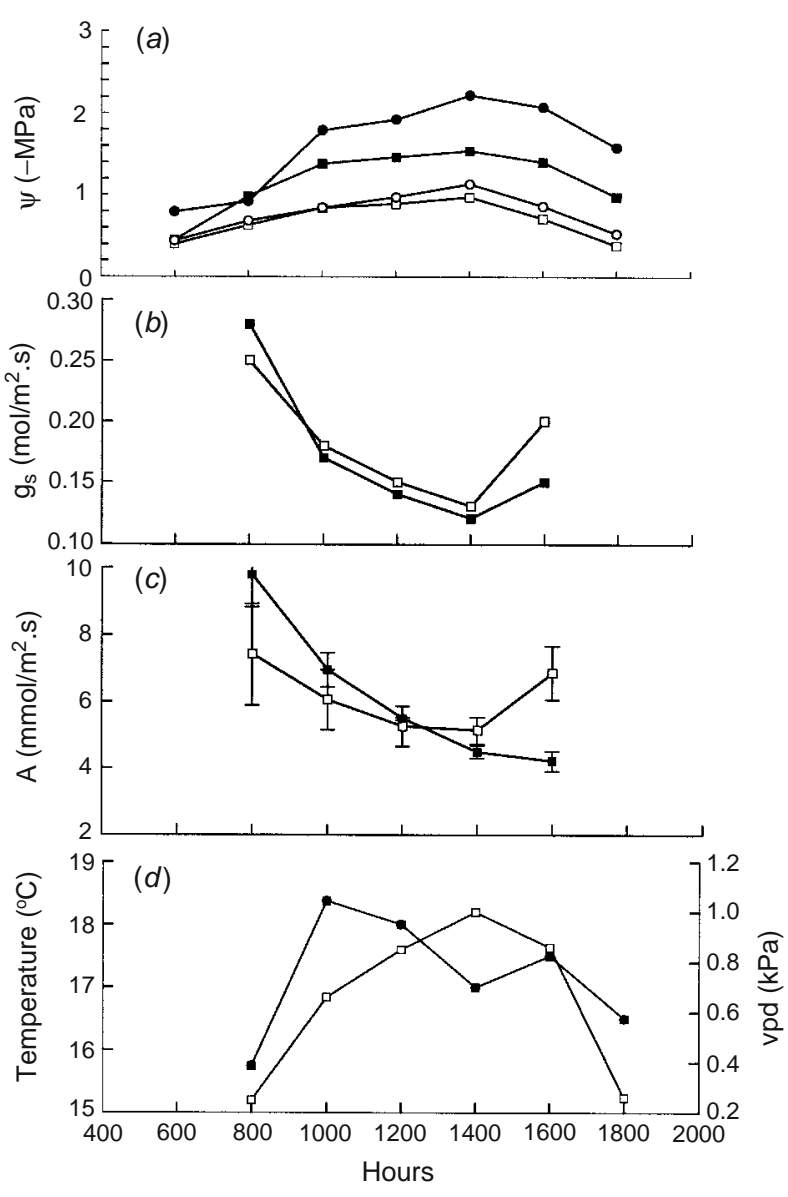

Fig. 2. Physiological responses of macadamia cv. Keauhou trees to diurnal atmospheric conditions in 1992 during the stage of floral development (August). (a) Water potential $(\psi)$ of stressed (closed symbols) and unstressed (open symbols) leaves $(\boldsymbol{\square}, \square)$, and racemes $(\bullet, \bigcirc)$; (b) stomatal conductance $\left(\mathrm{g}_{\mathrm{s}}\right) ;(c)$ photosynthesis $(\mathrm{A})$; and $(d)$ atmospheric conditions: ambient temperature $\left(\boldsymbol{\square}, \mathrm{T}^{\circ} \mathrm{C}\right)$ and vapour pressure deficit ( $\square$, vpd). Datum points are the means of 5 measurements each. Error bars are shown for A. For $\psi$ and $g_{s}$ s.e. $= \pm$ -0.01 to $-0.06 \mathrm{Mpa}$ and $\pm 0.01 \mathrm{~mol} / \mathrm{m}^{2} . \mathrm{s}$, respectively.

that from unstressed trees until after peak vapor pressure deficit (vpd) levels $(1.6 \mathrm{kPa})$ had been experienced at 1400-1600 hours. The diurnal response of stomatal conductance to stress was reflected in that of leaf photosynthesis.

Photosynthesis and stomatal conductance were highly but negatively correlated with water stress $(r=-0.86,-0.93$, respectively, $P<0.01)$ and with vpd $(r=-0.68,-0.75$, respectively, $P<0.01)$. Photosynthesis of unstressed leaves averaged c. $5.92 \pm 0.38 \mu \mathrm{mol} \mathrm{CO} 2 / \mathrm{m}^{2} . \mathrm{s}(n=15)$ compared with c. $2.23 \pm 0.26 \mu \mathrm{mol} \mathrm{CO}_{2} / \mathrm{m}^{2} . \mathrm{s}(n=20)$ for leaves on mildly stressed trees $(-1.8$ to $-2 \mathrm{MPa})$ in separate series of readings in both winter and late spring. Nevertheless, individual readings of up to $14.5 \mu \mathrm{mol} \mathrm{CO}_{2} / \mathrm{m}^{2}$.s were obtained from unstressed trees on several occasions.

\section{Yield}

Yield responses to stress treatments were variable from year to year. In the 1993 season, all stress treatments, except for that imposed during the nut growth/nut drop period, were similar to or higher than the controls (Table 2). In all other seasons and overall, yields of trees stressed during flowering, premature nut drop, and nut maturation stages tended to be lower than those of well-watered control trees. Yields tended to be lowest when stress was applied during the premature nut drop and nut maturation/oil accumulation stages. Stress during floral initiation did not affect yield or nut number per tree except in 1991 (Tables 2, 3). Higher yields were generally, but not always, reflected in higher relative nut numbers (Table 3).

\section{Quality}

There was a tendency for kernel recovery to be lower from stressed trees, although the data were variable (Table 4). During the favourable 1992-93 season when yields were high, for example, kernel recoveries from stressed treatments were similar to, and, in the case of premature nut drop, higher than, those of control trees. In general, however, kernel recovery of nuts stressed during nut maturation tended to be much lower than other stressed and control trees, indicating the sensitivity of macadamia to stress at this critical stage. There was also a tendency for kernel recovery to be higher when mild stress was imposed during the premature nut drop stage. Kernel size was unaffected in these nuts that were smaller [5.8 g cf. $7.3 \mathrm{~g}$ nut-in-shell (NIS) from the uncovered controls], the higher recovery being due to thinner shells. The percentage of first grade kernels was even more sensitive to stress at the nut maturation stage, particularly in the early years (Table 5).

\section{Vegetative growth}

Generally, tree growth (girth) was restricted, but not significantly so, by the mild stress compared with well-watered control trees with raincovers (Fig. 3). Well-watered trees without raincovers, however, had less girth growth, which was similar to that from stressed trees. Stress at floral initiation tended to restrict growth most, the rate of growth (slope) being significantly lower $(P<0.01)$ than that of other treatments over the duration of the experiment.

In the absence of water stress, trees produced the usual pattern of vegetative flushing: a minor peak in late winter-early spring and a major peak in the late summer-autumn period (Fig. 4). Vegetative flushing was, however, suppressed by stress but trees responded to re-watering by producing a massive burst of vegetative flush, which, in many cases, was delayed by several months. For example, control trees produced a small flushing peak in September 1990. The flush was delayed until November, December, and February, respectively, for trees stressed in April-May, September-October, and December-January 
Table 2. Yield of macadamia cv. Keauhou, nut-in-shell after mild water stress was imposed at various phenological stages from 1991 to 1995

Within years, means followed by the same letter do not differ significantly at $P=0.05$

\begin{tabular}{llcccrl}
\hline Stress imposed & 1991 & 1992 & 1993 & 1994 & 1995 & Total \\
\hline Floral initiation & $3.6 \mathrm{~cd}$ & 9.5 & $22.5 \mathrm{a}$ & $17.1 \mathrm{a}$ & 12.6 & 65.4 \\
Floral development & $0.1 \mathrm{~d}$ & 6.7 & $22.0 \mathrm{a}$ & $12.7 \mathrm{abc}$ & 6.5 & 47.4 \\
Premature nut drop & $3.0 \mathrm{~cd}$ & 7.0 & $11.9 \mathrm{c}$ & $7.6 \mathrm{c}$ & 7.4 & 40.2 \\
Nut maturation & $5.8 \mathrm{bc}$ & 5.2 & $16.0 \mathrm{bc}$ & $10.7 \mathrm{bc}$ & 15.2 & 52.7 \\
No stress (+ raincover) & $7.9 \mathrm{ab}$ & 11.1 & $19.0 \mathrm{ab}$ & $18.3 \mathrm{a}$ & 9.7 & 66.6 \\
No stress (- raincover) & $9.9 \mathrm{a}$ & 10.7 & $17.5 \mathrm{ab}$ & $16.2 \mathrm{ab}$ & 18.2 & 73.3 \\
s.d. & 2.5 & 3.0 & 3.5 & 3.6 & 4.6 & 15.3 \\
\hline
\end{tabular}

Table 3. Relative nut number (the number of nuts in each treatment as a percentage of those in Treatment 5 in the same year) of macadamia cv. Keauhou trees subjected to mild levels of water stress imposed at various phenological stages

Within years, means followed by the same letter do not differ significantly at $P=0.05$

\begin{tabular}{lccccc}
\hline Stress imposed & 1991 & 1992 & 1993 & 1994 & 1995 \\
\hline Floral initiation & $29 \mathrm{c}$ & 95 & $116 \mathrm{a}$ & $92 \mathrm{a}$ & 150 \\
Floral development & $1 \mathrm{c}$ & 72 & $113 \mathrm{a}$ & $66 \mathrm{ab}$ & 84 \\
Premature nut drop & $46 \mathrm{bc}$ & 81 & $62 \mathrm{~b}$ & $45 \mathrm{~b}$ & 107 \\
Nut maturation & $92 \mathrm{ab}$ & 80 & $90 \mathrm{ab}$ & $87 \mathrm{a}$ & 111 \\
No stress (+ raincovers) & 100 & 100 & 100 & 100 & 100 \\
No stress (- raincover) & $131 \mathrm{a}$ & 104 & $92 \mathrm{a}$ & $94 \mathrm{a}$ & 183 \\
(Mean number of nuts in Treat. 5) & $(1150)$ & $(1347)$ & $(2710)$ & $(2311)$ & $(1328)$ \\
s.d. & 37 & 36 & 18 & 18 & 69 \\
\hline
\end{tabular}

Table 4. Kernel recovery of macadamia cv. Keauhou nuts after mild levels of water stress were imposed at various phenological stages from 1991 to 1995

Within years, means followed by the same letter do not differ significantly at $P=0.05$

\begin{tabular}{lcclll}
\hline Stress imposed & 1991 & 1992 & 1993 & 1994 & 1995 \\
\hline Floral initiation & $30.2 \mathrm{ab}$ & $29.6 \mathrm{~b}$ & $33.3 \mathrm{~b}$ & $31.0 \mathrm{ab}$ & 32.2 \\
Floral development & $23.5 \mathrm{c}$ & $31.6 \mathrm{~b}$ & $34.4 \mathrm{ab}$ & $27.8 \mathrm{c}$ & 29.9 \\
Premature nut drop & $32.7 \mathrm{a}$ & $40.7 \mathrm{a}$ & $35.6 \mathrm{a}$ & $33.9 \mathrm{a}$ & 30.6 \\
Nut maturation & $24.9 \mathrm{bc}$ & $21.5 \mathrm{c}$ & $33.7 \mathrm{~b}$ & $28.2 \mathrm{bc}$ & 32.8 \\
No stress (+ raincovers) & $31.6 \mathrm{a}$ & $32.9 \mathrm{~b}$ & $33.6 \mathrm{~b}$ & $33.8 \mathrm{a}$ & 33.1 \\
No stress (- raincover) & $34.0 \mathrm{a}$ & $31.9 \mathrm{~b}$ & $33.6 \mathrm{~b}$ & $30.7 \mathrm{bc}$ & 33.7 \\
s.d. & 3.6 & 3.0 & 0.7 & 1.4 & 1.3 \\
\hline
\end{tabular}

Table 5. The percentage of first grade kernels of macadamia cv. Keauhou after mild levels of water stress were imposed at various phenological stages from 1991 to 1995 Within years, means followed by a letter in common do not differ significantly at $P=0.05$

\begin{tabular}{llcccc}
\hline Stress imposed & 1991 & 1992 & 1993 & 1994 & 1995 \\
\hline Floral initiation & $99.1 \mathrm{a}$ & $59.4 \mathrm{bc}$ & 93.2 & 64.4 & 85.9 \\
Floral development & $60.4 \mathrm{bc}$ & $79.4 \mathrm{ab}$ & 93.9 & 68.2 & 86.0 \\
Premature nut drop & $90.5 \mathrm{ab}$ & $96.7 \mathrm{a}$ & 92.6 & 85.6 & 88.6 \\
Nut maturation & $39.8 \mathrm{c}$ & $39.3 \mathrm{c}$ & 77.3 & 37.0 & 80.2 \\
No stress (+ raincovers) & $90.4 \mathrm{ab}$ & $100.0 \mathrm{a}$ & 83.7 & 83.4 & 90.7 \\
No stress (- raincover) & $93.6 \mathrm{a}$ & $86.8 \mathrm{a}$ & 98.0 & 86.4 & 97.8 \\
s.d. & 20.4 & 16.3 & 10.2 & 23.1 & 6.1 \\
\hline
\end{tabular}




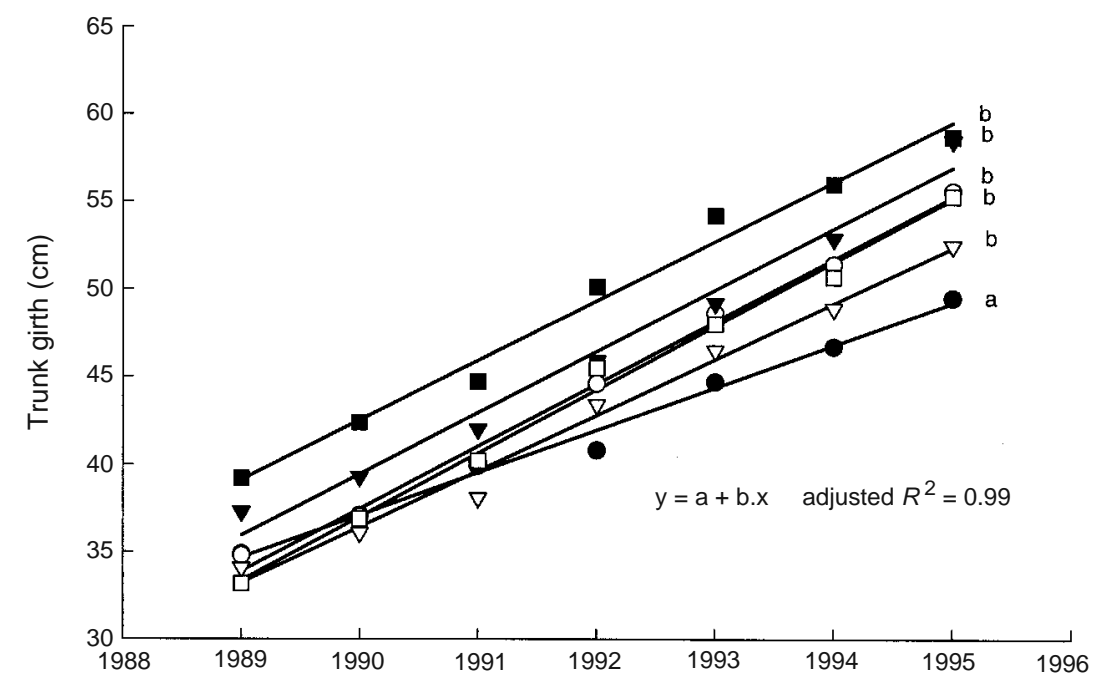

Fig. 3. Girth growth of macadamia trees exposed to mild water stress $(-1.5 \mathrm{MPa})$ at floral initiation $(\mathbf{O})$, inflorescence development $(\bigcirc)$, premature nut drop $(\mathbf{\nabla})$, and nut maturation $(\nabla)$, and no-stressed controls with $(\mathbf{\square})$ and without $(\square)$ raincovers. Fitted lines followed by the same letter indicate slopes that do not differ significantly $(P=0.05)$.

(Treatments 1, 2, and 4). Stress imposed in midsummer (Treatment 4) resulted in a dominant autumn flush peak, whereas stress in autumn (Treatment 1) resulted in a dominant spring peak.

Relatively short periods of mild stress had a cumulative effect on tree growth as indicated by data from the destructive harvest at the completion of the experiment (Table 6). Although differences were not significant, there was a trend of depression of tree growth by $10 \%$ for above-ground parts and $8 \%$ for those below ground. Leaf biomass, however, was greater from stressed trees. Nevertheless, it seems that in both stressed and unstressed trees, roots accounted for $28 \%$ of tree biomass.

\section{Flowering}

Although splitting and necrosis indicated sensitivity of perianth parts to mild stress applied at anthesis, there were no consistent responses of flowering intensity to either the time at which stress was imposed, or the severity or duration of stress, except for the extended period of stress (c. 60-70 days $)$ imposed at floral initiation in $1990(P=0.05)$ and 1991 (not significantly different), which reduced the number of flowers produced (data not shown).

\section{Discussion}

\section{Yield}

Although stress during the dormant, floral initiation stage had little effect on yield, stress during reproductive stages from flowering through to nut maturation tended to depress yields. Stress results in low water potential of racemes, leading to splitting and necrosis of perianth parts, failure of nut set, and reduced nut numbers. Despite the sensitivity of macadamia flowers to stress, there was little effect on flowering intensity. Seasonal conditions, such as temperatures and vpd, probably had over-riding effects and previous work has shown the capacity of macadamia trees to compensate for loss of inflorescences (Stephenson et al. $1989 a)$.

Stress at later stages of nut development, however, was probably partly due to indirect effects of reduced photosynthesis limiting energy for nut growth and oil accumulation. Stress during premature nut drop and nut maturation-early oil accumulation severely depressed yield, particularly marketable yield in the latter case. It seems that the reduction in yield in response to water stress was largely due to the smaller number of nuts, exacerbated by smaller nuts at the premature nut drop stage (5.8 $\mathrm{g}$ NIS) and the nut maturation stage $(6.4 \mathrm{~g})$ compared with $>6.6 \mathrm{~g}$ for other stressed treatments and $7.3 \mathrm{~g}$ for the covered control. Despite the smaller nuts from stress at premature nut drop, kernel size trended to be unaffected, kernel recovery being higher. Both water stress and atmospheric vpd exacerbate premature nut drop in macadamias (Stephenson and Gallagher 1987). In contrast, Trochoulias and Johns (1992) reported that irrigation of macadamias in an area with apparently adequate rainfall actually reduced nut size, presumably due to retention of more nuts.

The tendency for yields to be lower from well-watered trees with raincovers compared with those without indicates some adverse effects of raincovers on tree performance, although these appeared to be minor and inconsistent. In fact, some stressed treatments produced higher yields than the uncovered controls, particularly in 1993. The uncovered 


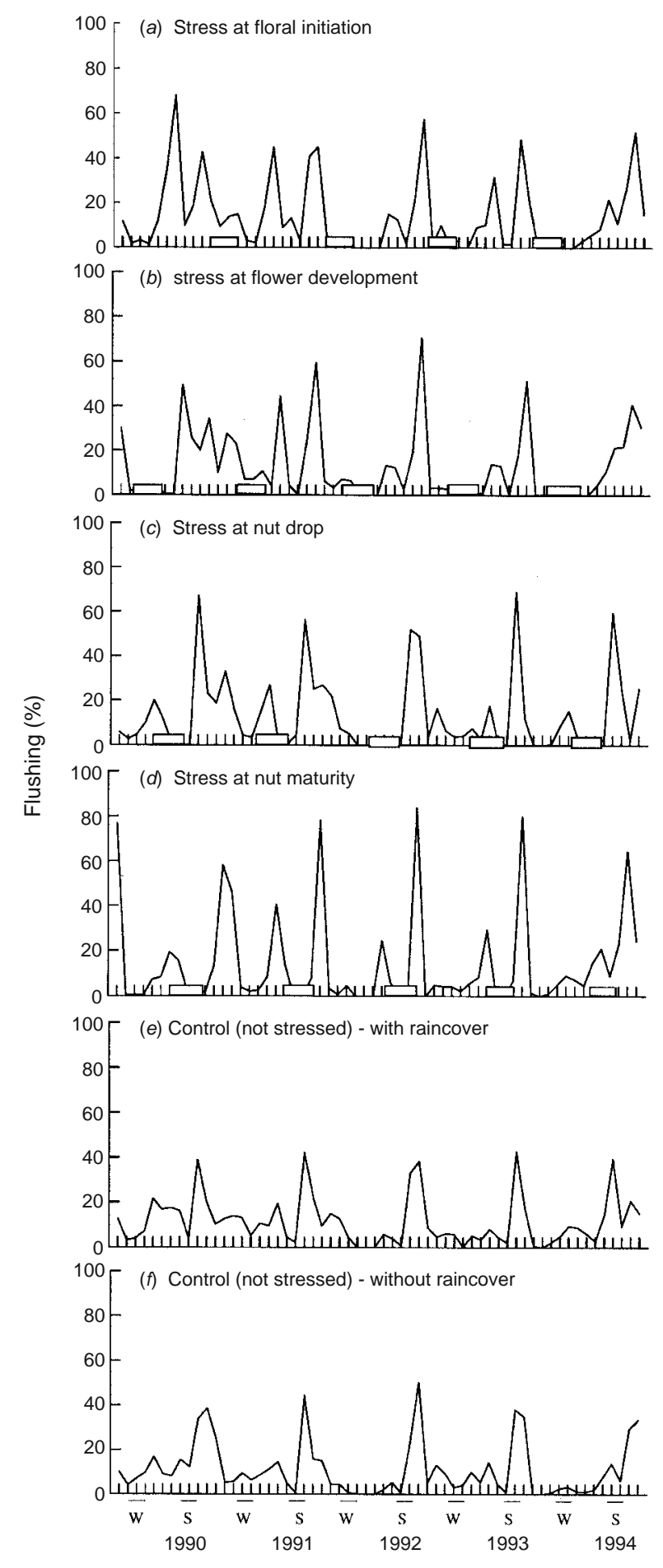

Fig. 4. Flushing patterns (the percentage of canopy surface vegetatively flushing) of macadamia trees in lysimeters exposed to mild water stress $(-1.5 \mathrm{MPa})$ at $(a)$ floral initiation, $(b)$ flowering/nut set, $(c)$ premature nut drop, and $(d)$ nut maturation, or $(e)$ no stress (with raincovers), and $(f)$ no stress (without raincovers). Open, horizontal bars indicate periods of stress.
Table 6. Average dry weight $(\mathrm{kg})$ of component parts of 10-year-old clonal macadamia trees (cv. Keauhou, HAES 246) across all treatments at completion of water stress experiment There are no significant differences between treatments

\begin{tabular}{lcc}
\hline Tree parts & Stressed & Unstressed \\
\hline Trunk & 14.4 & 18.4 \\
Branches & 143.2 & 161.2 \\
Leaf & 26.5 & 24.5 \\
Nut-in-husk & 8.9 & 12.1 \\
Total above-ground parts & 193.0 & 216.2 \\
Root stump & 16.6 & 14.1 \\
Large roots & 7.0 & 7.5 \\
Small roots & 51.9 & 60.7 \\
Total roots & 75.5 & 82.3 \\
Total tree & 268.5 & 298.5 \\
\hline
\end{tabular}

control trees also had lower girth growth than covered trees. Conditions with raincovers may have been less stressful due to reduced evaporation effectively buffering soil moisture. The influence of raincovers on the microclimate about the trunk/soil surface may have stimulated vegetative growth but the imposition of stress appears to counters this. Soil and/or canopy temperatures, for example, would certainly be modified.

The shorter periods of stress during flowering/nut set and premature nut drop stages resulted in less severe yield depression and larger relative retention of nuts per tree in 1992 compared with 1991. In contrast, the lower number of stressful days during nut maturation/oil accumulation in 1991-92 was not reflected in higher nut retention and yield in 1992. These were even lower than in the previous season. The progressive reduction of the stress period showed that even 20 days of mild stress resulted in depressed yield and quality during the critical floral development, premature nut drop, and nut maturation periods.

\section{Quality}

The enhancement of kernel recovery by stress during premature nut drop was probably due to early adjustment of crop load, thus reducing energy investment in nuts, which may subsequently drop before they reach maturity. Nevertheless, stress at this stage also had adverse effects on shell development in some years, including distortion, breakdown, and a tendency for the thin, underdeveloped shells to split. Grierson et al. (1982) cited various authors who showed that moderate stress can improve the quality of tree fruits and other crops. However, the extent of stress (severity and time of exposure) is critical.

Very low kernel recoveries resulting from stress at nut maturation rendered the crop uneconomic and unmarketable; kernels were discoloured and shrivelled. Generally, the effect of stress on quality at other stages was less severe. It seems clear that the nut maturation stage is particularly sensitive due to high energy requirements. The reduction in 
photosynthesis in water-stressed trees would account for the sensitivity of macadamia yield and quality to stress prior to, or during, the critical oil accumulation stage. This is consistent with the conclusion of Awada et al. (1967) that high moisture was essential for nut maturity.

Despite the lack of statistically significant differences, stress during nut maturation clearly appeared to suppress oil accumulation and, hence, the percentage of first grade kernel. Irrigation actually resulted in reduction of first grade kernels by $2.8 \%$ in the work of Trochoulias and Johns (1992), apparently due to luxury levels of water consumption. Under drier conditions in Hawaii, however, quality was higher with irrigation (Bittenbender et al. 1998).

\section{Physiological responses}

The pattern of water potential in response to stress was similar to that of a range of fruit trees presented by Jones et al. (1985). The relatively low levels of photosynthesis reported here are similar to those obtained with container-grown macadamia trees at ambient $\mathrm{CO}_{2}$ (Hilde de Kruiff, pers. comm. 1994). In de Kruiff's study, field-grown macadamia trees had consistently higher photosynthesis $\left(8.8 \mu \mathrm{mol} \mathrm{CO}_{2 /} \mathrm{m}^{2} . \mathrm{s}\right)$ than containerised trees under similar conditions. These rates are still relatively low. Lloyd (1991) reported maximum levels of $\mathrm{A}$ of $14 \mu \mathrm{mol} \mathrm{CO} \mathrm{CO}_{2} / \mathrm{m}^{2}$.s under laboratory conditions (ambient $\mathrm{CO}_{2}$ and photosynthetic photon flux of $1500 \mu \mathrm{mol}$ quanta $/ \mathrm{m}^{2} . \mathrm{s}$ ). This is comparable with the highest readings observed in this study from trees growing in lysimeters.

Enhanced photosynthesis by stressed leaves early in the day may be related to very low levels of vpd $(0.2 \mathrm{kPa})$. Conversely, the lower photosynthesis by stressed leaves in the latter part of the day is probably induced by low root-zone water potential, via root signals, causing sustained stomatal closure, and a reduced capacity for photosynthetic rates to recover after the midday depression, whereas unstressed trees recovered. Stephenson et al. (1989b) had previously shown that the critical water potential below which stomata close tightly was $c$. -1.8 to $-2 \mathrm{MPa}$ and, up to that critical level, the stomatal closure was essentially linear. The strong influence of vpd on photosynthesis and stomatal conductance may confound the interpretation of physiological responses to water deficits in these 'field-grown' trees.

\section{Vegetative growth}

Trunk growth and flushing was restricted by stress treatments, which also had a cumulative effect in depressing root growth. Trochoulias and Johns (1992) reported that irrigation did not affect macadamia tree growth, although the unirrigated trees in their study may not have been sufficiently stressed.
Larger and earlier winter/spring flushing peak after stress at floral initiation, and relatively high yields, are consistent with correlations reported by Stephenson et al. (1986b), and Stephenson and Gallagher (1989). Since substantial changes in phenology apparently influence macadamia yields, the judicious application of mild levels of water stress may be useful in manipulating macadamia trees to achieve higher yields.

\section{Water consumption}

The higher daily water use during the nut maturation stage reflects the hot, dry summer season. The tendency for stressed trees to have fewer small feeder roots than unstressed trees, although not significant, indicates root sensitivity to the cumulative effects of stress even though stress treatments had not been imposed during the 12 months preceding the destructive tree harvest. Several authors cited by Jones et al. (1985) have shown that roots proliferate mainly within wetted soil. Stressed trees actually produced more foliage than unstressed trees, due to the stimulation of leaf flush after re-watering at the end of the stressed period and subsequently. Active leaf flushes following re-watering would contribute to a larger evaporative surface and hence greater water use. It would be useful to monitor patterns of root flushing in response to, and recovery from, stress and to assess the dynamics of root growth and that of vegetative flushing on yield.

\section{Conclusions}

Short periods of stress at any of the reproductive stages are likely to reduce both yield and quality of macadamia nuts, and where water resources are limited, irrigation should be restricted to these critical stages, particularly premature nut drop when yield is severely depressed and the latter stages of nut maturation when both yield and quality are adversely affected by stress, making kernels unmarketable.

\section{Acknowledgments}

Financial assistance from the Australian Macadamia Society, the Horticultural Research and Development Corporation (now Horticulture Australia Limited), and the Queensland Department of Primary Industries is gratefully acknowledged. We thank Mr A. J. Pignata for his significant contribution in the field.

\section{References}

Awada M, Warner RM, Watanabe Y (1967) Effect of soil moisture stress on growth and yield of macadamia. Hawaii Agricultural Experiment Station Bulletin No. 69.

Bittenbender HC, Hue NV, Fleming K, Brown H (1998) Sustainability of organic fertilization of macadamia with macadamia husk-manure compost. Communications in Soil Science and Plant Analysis 29, 409-419.

Genstat (2000) Genstat for Windows. Release 6.1. 6th edn (VSN International Ltd: Oxford) 
Grierson W, Soule J, Kawada K (1982) Beneficial aspects of physiological stress. Horticultural Reviews 4, 247-271.

Jones HG, Lakso AN, Syvertsen JP (1985) Physiological control of water status in temperate and subtropical fruit trees. Horticultural Reviews 7, 301-344.

Lloyd J (1991) Modelling stomatal responses to environment on Macadamia integrifolia. Australian Journal of Plant Physiology 18, 649-660.

Ritchie GA, Hinckley TM (1975) The pressure chamber as an instrument for ecological research. Advances in Ecological Research 9, 165-254.

Scholander PF, Hammel HT, Hemmingsen EA, Bradstreet ED (1964) Hydrostatic pressure and osmotic potential in leaves of mangroves and some other plants. Proceedings of the National Academy of Science, USA, 52, 119-125.

Stephenson RA, Bridge A, Gallagher EC (1988) A lysimeter to study Queensland tree crops. Queensland Agricultural Journal 114, 9-12.

Stephenson RA, Cull BW, Mayer DG (1986) Effects of site, climate, flushing, and soil and leaf nutrient status on yields of macadamia in South East Queensland. Scientia Horticulturae 30, 227-235.
Stephenson RA, Gallagher EC (1987) Effects of temperature, tree water status and relative humidity on premature nut drop of macadamia. Scientia Horticulturae 33, 113-121.

Stephenson RA, Gallagher EC (1989) Timing of nitrogen application to macadamias I. Tree nitrogen status and vegetative growth Australian Journal of Experimental Agriculture 29, 569-574.

Stephenson RA, Gallagher EC, Rasmussen TS (1989a) Effects of growth manipulation on carbohydrate reserves of macadamia trees. Scientia Horticulturae 40, 227-235.

Stephenson RA, Ko HL, Gallagher EC (1989b) Plant-water relations of stressed, non-bearing macadamia trees. Scientia Horticulturae 39, 41-53.

Trochoulias T, Johns GG (1992) Poor response of macadamia (Macadamia integrifolia Maiden and Betche) to irrigation in a high rainfall area in subtropical Australia. Australian Journal of Experimental Agriculture 32, 507-512.

Manuscript received 4 July 2002, accepted 23 September 2002 